\title{
Effects of pesticide exposure on reproductivity of male groundnut farmers in Kyauk Kan village, Nyaung-U, Mandalay region, Myanmar
}

This article was published in the following Dove Press journal: Risk Management and Healthcare Policy

\author{
Thant Zaw Lwin ${ }^{1,2}$ \\ Aye Aye Than ${ }^{3}$ \\ Aung Zaw Min ${ }^{4}$ \\ Mark Gregory Robson ${ }^{5}$ \\ Wattasit Siriwong ${ }^{2,6}$ \\ 'Department of Preventive and \\ Social Medicine, Defence Services \\ Medical Academy, Yangon, Myanmar; \\ ${ }^{2}$ Center for Risk Analysis and Health \\ Surveillance (C-RAHS), College of \\ Public Health Sciences, Chulalongkorn \\ University, Bangkok, Thailand; \\ ${ }^{3}$ Defence Services Orthopedics \\ Hospital, Yangon, Myanmar; ${ }^{4}$ Military \\ Institute of Nursing and Paramedical \\ Sciences, Yangon, Myanmar; ${ }^{5}$ School of \\ Environmental and Biological Sciences, \\ Rutgers University, New Brunswick, \\ NJ, USA; ${ }^{6}$ College of Public Health \\ Sciences, Chulalongkorn University, \\ Bangkok, Thailand
}

Introduction: Kyauk Kan village of Nyaung-U, Mandalay region, Myanmar is one of the most famous groundnut-growing zones and has been exposed to pesticides.

Methods: This study design provided evaluation of within-person changes in the season across growing and nongrowing periods. A cross-sectional study was performed to identify health problems related to organophosphate pesticide (OP) exposure, to explore the protected use of this pesticide among 400 participants in the community by face-to-face interviews, and to determine the reproductive effects of OP exposure by using biomarkers of 100 male groundnut farmers aged 18-49 years.

Results: The mean age of the participants was $37.5 \pm 9.45$ years. Analysis revealed statistically significant differences in seminal parameters $(P<0.05$ for $\mathrm{pH}$, viscosity, motility, morphology, and sperm count) and in a reproductive hormonal assay $(P<0.05$ in follicle-stimulating hormone and testosterone) between the growing and nongrowing periods. Blood-cholinesterase levels of plasma cholinesterase in the growing period were significantly higher than those in the nongrowing period $(P<0.05)$.

Conclusion: Our results suggest that chronic exposure related to OP dose may reduce potential male reproductivity.

Keywords: pesticide exposure, semen quality, serum hormone level, blood cholinesterase, male reproductivity

\section{Introduction}

Exposure to harmful environmental agents affects human reproductive capacity. ${ }^{1}$ Many chemical and physical agents that were designed for industrial and agricultural purposes have led to a rise in male reproductive problems, such as infertility, sexual dysfunction, cryptorchidism, hypospadias, and testicular cancer. ${ }^{2,3}$

Agriculture is an important part of the Myanmar economy, and pesticide poisoning is a potential agricultural hazard. Many Myanmar farmers have not been educated about chemical insecticides. ${ }^{4}$ In Myanmar, agricultural pesticides, including the organophosphate (OP), organochlorine, and carbamate groups, are commonly used. ${ }^{5}$ Two to five pesticides are frequently mixed and utilized. These pesticides may be used without caution or inappropriately; moreover, the empty containers may not be disposed of appropriately. ${ }^{1}$

Inappropriate brain acetylcholinesterase (AChE) activity and monoamine levels causing impaired gonadal development and alterations in hypothalamic and pituitary endocrine functions have been found among those who use OP insecticides within agri-
Correspondence: Wattasit Siriwong College of Public Health Sciences, I0th floor, Institute Building, Chulalongkorn University, 3 Soi Chulalongkorn, 62 Phayathai Road, Bangkok 10330, Thailand Tel +6622188184

Fax +66 22556046

Email wattasit.s@chula.ac.th 
cultural settings. Such insecticides have been found to affect reproductive function, along with the production and function of hormones that regulate spermatogenesis. ${ }^{6,7}$ Decreased testosterone reduces libido, causes erectile dysfunction, and affects sperm numbers and sperm health. ${ }^{8}$

OP insecticides exert toxic effects and exist as phosphoric or thiophosphoric acid esters. As they inhibit AChE activity, when men are exposed to OP insecticides, this may result in altered sperm structure and function, contributing toward deterioration in human semen quality and triggering infertility. Its mechanism of action is to inhibit brain AChE activity and disturb pituitary gonadotropin. ${ }^{9}$ At maximum dosages, OP insecticides have been shown to exert cytotoxic effects on sperm and to reduce both sperm-fertilizing ability and sperm motility. ${ }^{10}$ Owing to these negative effects on health, it is necessary to understand knowledge and practices associated with pesticide use among agricultural workers. ${ }^{11}$ This study aimed to identify the effect of pesticide exposure on the reproductive systems of male groundnut farmers, based on interviews and biomarkers in Kyauk Kan village, Nyaung-U, Mandalay Province, Myanmar.

\section{Methods}

\section{Research design and methodology}

This research consisted of two descriptive studies: an observational study and a laboratory study. The first cross-sectional study, referred to here as the observational study, identified health problems related to pesticide exposure and explored awareness of the safe handling of pesticides among 400 participants of 818 groundnut farmers in the community via face-to-face interviews. This was followed by another crosssectional study involving 100 males in Kyauk-Kan village who had experienced problems with pesticide use and/or had lived in the study area for more than 5 years prior to the study. Laboratory-study subjects, aged 18-49 years, were selected from the participants of the first study. This second study aimed to determine the reproductive effects of OP pesticides among chronically exposed subjects during the growing and nongrowing periods using such biomarkers as semen profile, serum hormone, and blood-cholinesterase (ChE) level. These parameters were evaluated in the growing and nongrowing season. Exclusion criteria were farmers who had a history of vasectomy, were using exogenous hormones, and were unwilling to give sperm or blood samples.

The studies were approved by the Myanmar Medical Research Center of Ethics Review Committee (ERC 00151 6, Ethics/DMR/2016/037), Department of Medical Research,
Ministry of Health, and the government of Myanmar. All subjects were informed of the study objectives and informed that all information and biological samples were confidential. Written informed consent was provided by all subjects, and they had the right to withdraw from the study at any time, with no adverse consequences. As an incentive, each subject was paid 5,000 Myanmar kyat (approximately US\$5) to participate.

\section{Selection of study area}

Kyauk Kan village, Nyaung-U, Mandalay Province, Myanmar is known for growing groundnuts. Several pesticides are continually used in this area. No previous studies of the effect of pesticide exposure have been conducted in this village. In Kyauk Kan at the time of the studies, there were 182 households comprising 366 males and 452 females, 642 of whom were of working age. ${ }^{12}$

\section{Questionnaire}

Each subject completed a questionnaire in which they provided information about sociodemographic characteristics, knowledge, and practices regarding pesticide use and safety precautions used. Specific questions about pesticide use indicated the type, frequency, and disposal of empty pesticide containers and the type and frequency of use of personal protective equipment.

\section{Sample collection}

Semen and blood samples were collected from each person twice: once during the growing season (June-October) and once during the nongrowing season (November-April).

\section{Semen collection and seminal fluid analysis}

All participants were asked to avoid ejaculation for 2-3 days before semen collection. Semen samples were analyzed on site within 1 hour of collection. For the purposes of privacy, semen collection took place in a private room, and the procedure was overseen entirely by the primary investigator. Unacceptable specimens were defined as containers that were cracked, broken, or leaking. All semen samples were collected carefully. The investigator then recorded the date of collection and time of ejaculation, and each sample was systematically coded. Next, all semen samples were kept in an incubator at $37^{\circ} \mathrm{C}$ before being liquefied, which took about 20-30 minutes, and subsequently examined. Semen samples were analyzed for volume, $\mathrm{pH}$, viscosity, motility, morphol- 
ogy, and sperm count following World Health Organization (WHO) guidelines. ${ }^{13,14}$

\section{Blood-hormone analysis}

A $10-\mathrm{mL}$ plastic syringe was used to collect blood samples from the farmers. Next, samples were centrifuged at room temperature until the serum had separated. Follicle-stimulating hormone (FSH), luteinizing hormone ( $\mathrm{LH}$ ), and testosterone levels were then measured. ${ }^{15}$ This study was focused on the issue of whether environmental chemicals cause altered hormone levels through various biological mechanisms and target sites, ranging from effects on hormone receptors to effects on hormone synthesis, secretion, or metabolism.

\section{Blood-cholinesterase testing}

Using a finger-prick technique, $10 \mu \mathrm{L}$ blood samples were collected from the farmers after the end of their shifts. A Test-Mate ChE kit (model 400; EQM Research, Cincinnati, $\mathrm{OH}, \mathrm{USA}$ ) was used in this study. Erythrocyte AChE indicated chronic or long-term exposure to OP pesticides, while plasma $\mathrm{ChE}(\mathrm{PChE})$ indicated short-term exposure to detect acute poisoning early. ${ }^{16}$

\section{Data analysis}

Continuous variables are expressed as means $\pm \mathrm{SD}$. Wilcoxon signed-rank tests were used to compare differences in seminal profile, blood-hormone level, and blood-ChE level of the study subjects between the growing and nongrowing seasons. Shapiro-Wilk tests $(P>0.05),{ }^{17}$ along with visual inspection of the subjects' histograms, normal Q-Q plots, and box plots, showed that all variables (semen analysis, blood-hormone levels, and blood-ChE levels) were abnormally distributed, so we used the median for each of the biomarker variables for both growing and nongrowing seasons. SPSS version 16 was used for statistical analysis. ${ }^{18}$ Two-sided $P<0.05$ was considered statistically significant.

\section{Quality control}

For seminal analysis, all samples were prepared by the investigators to meet the standard required by the qualitycontrol laboratory. All semen samples were gathered and tested by qualified personnel based on WHO (1992 and 1999) guidelines. ${ }^{19,20}$ For hormonal analysis, we used an Elecsys PreciControl Universal 1 and 2. Controls for the various concentration ranges should be performed as single determinations at least once every 24 hours when the test is in use (once per reagent kit and after each calibration).

\section{Results}

For the observational study, 400 applicants were screened for eligibility criteria. Of these, 100 male groundnut farmers aged 18-49 years were selected by a simple random-sampling method. In the laboratory study, the farmers had a mean age of 37.5 years $( \pm 9.45 \mathrm{SD})$. Half the respondents were of primary and middle education level, with a mean body-mass index of $18.34 \pm 2.14$, classified as within a lower-than-normal range (18.5-24.9) according to the WHO. ${ }^{21}$ Baseline characteristics are shown in Table 1.

\section{Seminal fluid analysis}

Table 2 shows the statistically significant differences $(P<0.05)$ found between the biomarkers of seminal analysis (viscosity, motility, morphology, and sperm count) in the growing and nongrowing periods using the Wilcoxon signed-rank test. The results of the sperm analysis revealed that $74 \%$ of the farmers had oligozoospermia ${ }^{22}$ - a higher than average figure - in the growing period, but this figure decreased to $46 \%$ in the nongrowing period, because the farmers have less exposure to pesticide in the nongrowing season. These findings may lead to further evidence that occupational exposure to other pesticide residues adversely impacts semen quality. The results of the semen analysis revealed that participants' sperm count was significantly lower during the growing period than the nongrowing period.

\section{Reproductive hormone assay}

Table 3 shows statistically significant differences found in serum-hormone levels ( $P<0.05$ for $\mathrm{FSH}$ and testosterone) in the growing and nongrowing periods. Virulent disclosure can modify the manufacture, discharge, or action of hormones

Table I Demographic characteristics of study participants in growing and nongrowing periods $(n=100)$

\begin{tabular}{|l|l|}
\hline & Prevalence \\
\hline Age (years) & \\
\hline Mean \pm SD (range) & $37.5 \pm 9.45$ (18-49) \\
\hline Body-mass index (kg/m $\mathbf{2})$ & \\
\hline Mean \pm SD (range) & $18.34 \pm 2.14$ (I8.5-24.9) \\
\hline Education (\%) & \\
\hline Primary school level & 34 \\
\hline Middle school level & 39 \\
\hline High school level & 19 \\
\hline University level & 8 \\
\hline Smoking during work (\%) & 65 \\
\hline Eating and drinking during work (\%) & 76 \\
\hline Alcohol consumption habits (\%) & 45 \\
\hline
\end{tabular}


that monitor spermatogenesis. A decline in testosterone can also reduce both a man's desire for sexual intercourse and his sexual functioning. Broadly speaking, chemical or physical promoters can severely damage a man's testicles, sperm cells, or mature sperm. Such damage can lead to a deterioration in sperm count, an absence of sperm, and reduction in their motility or function. ${ }^{8}$

\section{Blood-cholinesterase testing}

ChE values were divided by using median values for cutoff points for two levels: abnormal and normal. ${ }^{23}$ If the value was $\leq 3.15 \mathrm{U} / \mathrm{mL}$ for $\mathrm{AChE}, \leq 25.4 \mathrm{U} / \mathrm{g}$ hemoglobin for $\mathrm{HAChE}$, and $\leq 1.61 \mathrm{U} / \mathrm{mL}$ for $\mathrm{PChE}$ in the growing period and $\leq 3.13$ $\mathrm{U} / \mathrm{mL}$ for $\mathrm{AChE}, \leq 27.5 \mathrm{U} / \mathrm{g}$ hemoglobin for $\mathrm{HAChE}$ and $\leq 1.28 \mathrm{U} / \mathrm{mL}$ for PChE in the nongrowing period, this was considered to represent an "abnormal" level, thus indicating that participants could potentially have pesticide poisoning. If values of AChE, HAChE, and PChE were $>3.15,>25.4$, and $>1.61 \mathrm{U} / \mathrm{mL}$ in the growing period and $>3.13,>27.5$, and $>1.28 \mathrm{U} / \mathrm{mL}$ in the nongrowing period, respectively, this indicated a "normal" level. Table 4 shows the effect of exposure to OP pesticides among the farmers in relation to blood $\mathrm{ChE}$.

\section{Discussion}

In Myanmar, most farmwork is usually carried out by male workers. Nearly half the respondents had 10-12 years' experience of working on a farm, and the number of years they had worked with pesticides was even higher, because groundnut growing represents a major source of work in the area. After finishing primary school, they immediately began working in the groundnut industry. Most of the farmers applied pesticides to their fields for about 5 hours per day in the paddy fields, highlighting that farmers who work in paddy fields could be exposed to pesticides. Most of these farmers mixed, loaded, and sprayed pesticides by themselves.

Table 2 Comparison of semen-quality parameters in respondents who had been exposed to organophosphate pesticides in growing and nongrowing periods $(n=100)$

\begin{tabular}{|c|c|c|c|c|c|c|c|c|c|}
\hline \multirow{2}{*}{$\begin{array}{l}\text { Semen } \\
\text { quality }\end{array}$} & \multicolumn{3}{|c|}{ Growing period } & \multicolumn{3}{|c|}{ Nongrowing period } & \multirow{2}{*}{$\begin{array}{l}\text { Wilcoxon } \\
\text { z-value }\end{array}$} & \multirow{2}{*}{$\begin{array}{l}\text { P-value } \\
\text { (two- } \\
\text { tailed) }\end{array}$} & \multirow{2}{*}{$\begin{array}{l}\text { Reference } \\
\text { value }\end{array}$} \\
\hline & $\begin{array}{l}\text { Normal, } \\
\text { n (\%) }\end{array}$ & $\begin{array}{l}\text { Abnormal, } \\
\text { n (\%) }\end{array}$ & $\begin{array}{l}\text { Median } \\
\text { (range) }\end{array}$ & $\begin{array}{l}\text { Normal, } \\
\text { n (\%) }\end{array}$ & $\begin{array}{l}\text { Abnormal, } \\
\text { n (\%) }\end{array}$ & $\begin{array}{l}\text { Median } \\
\text { (range) }\end{array}$ & & & \\
\hline Volume & $25(25 \%)$ & 75 (75\%) & $1.65(0.20-4.50)$ & 48 (48\%) & 52 (52\%) & $1.60(0.5-6.4)$ & -1.095 & 0.274 & $2-5 \mathrm{cc}$ \\
\hline $\mathrm{pH}$ & $58(58 \%)$ & $42(42 \%)$ & ${ }^{b}(6.00-8.50)$ & $96(96 \%)$ & $4(4 \%)$ & $(7.00-8.50)$ & -6.076 & $\mathrm{NC}$ & $7.2-7.8$ \\
\hline Viscosity & $23(23 \%)$ & 77 (77\%) & $45.0(15-120)$ & $58(58 \%)$ & $42(42 \%)$ & $30.0(10.0-120)$ & -4.858 & $0.000^{\mathrm{a}}$ & Within 30 minutes \\
\hline Motility & $9(9 \%)$ & $91(91 \%)$ & $50(0.0-90.0)$ & $13(13 \%)$ & $87(87 \%)$ & $30.0(3.0-80.0)$ & -2.838 & $0.005^{\mathrm{a}}$ & $>80 \%$ motile \\
\hline Morphology & $5(5 \%)$ & $95(95 \%)$ & $67.5(0-100)$ & $9(9 \%)$ & 91 (91\%) & $75.0(40.0-100)$ & -4.338 & $0.000^{\mathrm{a}}$ & $\begin{array}{l}\text { Tail } \sim 90 \% \text { total } \\
\text { length }\end{array}$ \\
\hline Sperm count & $23(23 \%)$ & 77 (77\%) & $30.5(0-1176)$ & 54 (54\%) & $46(46 \%)$ & $64(8.0-464.0)$ & -4.852 & $0.000^{\mathrm{a}}$ & $60-150 \times 10^{6}$ \\
\hline
\end{tabular}

Notes: ${ }^{a} \mathrm{P}<0.05$ (Wilcoxon signed-rank test). ${ }^{\mathrm{b}} \mathrm{A} \mathrm{pH}$ value cannot have a median.

Abbreviation: NC, no comparison.

Table 3 Comparison of serum hormonal levels in respondents who were exposed to organophosphate pesticides in the growing and non-growing period $(n=100)$

\begin{tabular}{|c|c|c|c|c|c|c|c|}
\hline & & \multicolumn{2}{|l|}{ Growing period } & \multicolumn{2}{|c|}{ Non-growing period } & \multirow{2}{*}{$\begin{array}{l}\text { Wilcoxon } \\
\text { z-value }\end{array}$} & \multirow{2}{*}{$\begin{array}{l}\text { P-value } \\
\text { (two-tailed) }\end{array}$} \\
\hline & & Frequency, n (\%) & Median (range) & Frequency & Median (range) & & \\
\hline \multirow[t]{3}{*}{ FSH (1.5-1 2.4) } & Low & $2(2 \%)$ & $4.35(1.3-27.5)$ & $2(2 \%)$ & $4.81(1.45-27.8)$ & -2.326 & $0.02^{\mathrm{a}}$ \\
\hline & Normal & $92(92 \%)$ & & $90(90 \%)$ & & & \\
\hline & High & $6(6 \%)$ & & $8(8 \%)$ & & & \\
\hline \multirow[t]{3}{*}{ LH (I.7-8.6) } & Low & 0 & $6.79(2.68-18.11)$ & $\mathrm{I}(\mathrm{I} \%)$ & $6.65(1.29-21.7)$ & -0.951 & 0.342 \\
\hline & Normal & $68(68 \%)$ & & 75 (75\%) & & & \\
\hline & High & $32(32 \%)$ & & $24(24 \%)$ & & & \\
\hline \multirow{3}{*}{$\begin{array}{l}\text { Testosterone } \\
(2.84-8.0)\end{array}$} & Low & $6(6 \%)$ & $5.17(I .84-\mid I .4 I)$ & $6(6 \%)$ & $5.46(2.15-14.36)$ & -2.876 & $0.004^{a}$ \\
\hline & Normal & $88(88 \%)$ & & $82(82 \%)$ & & & \\
\hline & High & $6(6 \%)$ & & $12(12 \%)$ & & & \\
\hline
\end{tabular}

Note: ${ }^{\mathrm{P}}<0.05$ (Wilcoxon signed-rank test).

Abbreviations: $\mathrm{FSH}$, follicle-stimulating hormone; $\mathrm{LH}$, luteinizing hormone. 
Table 4 Comparison of blood-cholinesterase levels in respondents who were exposed to organophosphate pesticides in growing and nongrowing periods $(n=100)$

\begin{tabular}{|c|c|c|c|c|c|c|c|}
\hline & & \multicolumn{2}{|l|}{ Growing period } & \multicolumn{2}{|c|}{ Nongrowing period } & \multirow{2}{*}{$\begin{array}{l}\text { Wilcoxon } \\
\text { z-value }\end{array}$} & \multirow{2}{*}{$\begin{array}{l}P \text {-value } \\
\text { (two-tailed) }\end{array}$} \\
\hline & & Frequency, n (\%) & Median (range) & Frequency & Median (range) & & \\
\hline \multirow[t]{2}{*}{ AChE } & Normal & $39(39 \%)$ & $3.15(2.01-5.46)$ & $50(50 \%)$ & $3.13(1.67-4.69)$ & -1.700 & 0.089 \\
\hline & Abnormal & $61(61 \%)$ & & $50(50 \%)$ & & & \\
\hline \multirow[t]{2}{*}{ HAChE } & Normal & $50(50 \%)$ & $25.4(6.2-17.2)$ & 52 (52\%) & $27.5(18.80-42.40)$ & -3.462 & $0.00 \mathrm{I}^{\mathrm{a}}$ \\
\hline & Abnormal & $50(50 \%)$ & & $48(48 \%)$ & & & \\
\hline \multirow[t]{2}{*}{ PChE } & Normal & $43(43 \%)$ & $\mathrm{I} .6 \mathrm{I}(0.7-3.28)$ & $50(50 \%)$ & $1.28(0.01-3.24)$ & -5.269 & $0^{\mathrm{a}}$ \\
\hline & Abnormal & $57(57 \%)$ & & $50(50 \%)$ & & & \\
\hline
\end{tabular}

Notes: ${ }^{a}<<0.05$ (Wilcoxon signed-rank test).

Abbreviations: AChE, acetylcholinesterase; HAChE, hemoglobin-adjusted AChE; PChE, plasma cholinesterase.

All the study participants were groundnut-growing farmers who always used chemical pesticides that could conquer pests and symptoms. Most of them were familiar with two to three types of chemical pesticide that could be applied to their groundnut crops. They would spray chlorpyrifos four or five times on the same crop using a motorized sprayer. Moreover, they always used large amounts of pesticide (exceeding the recommended dosages stated on the pesticide label) and mixed different kinds of pesticides together. None of them had ever been tested for pesticide contamination. In addition, they did not wear any personal protective equipment (PPE), such as rubber gloves or boots, to protect them from the pesticides.

However, for the farmworkers in this study, knowing about PPE was not enough to ensure chemical safety. Therefore, further education regarding PPE is recommended to reduce the risks of pesticide toxicity among farmworkers. To promote the safe handling of chemical pesticides, educating the workers is vital to achieve necessary behavioral changes. Health personnel need to educate farmworkers about the safe handling of pesticides and keep themselves up to date on current knowledge about pesticides. This is because disseminating information about safety measures through online media is not particularly effective, especially regarding the use of protective clothes or aprons. A more effective way of educating the workforce is for health workers to explain the pros and cons.

Improper usage of OP pesticides has a negative effect on the male reproductive system and can lead to reduced sperm density and motility, obstructed spermatogenesis, reduced sperm counts, a rise in abnormal sperm morphology, and changes in plasma levels of testosterone, FSH, and LH. In this study, all semen-quality and serum-hormone variables showed significant variations between the growing period and the nongrowing period. A similar result was found by Hossain et al, ${ }^{24}$ who explored associations between exposure to pesticides belonging to a variety of classes and poorer sperm function. Moreover, Perez et $\mathrm{al}^{25}$ reported that increased serum LH and FSH and reduced testosterone were related to OP exposure. Other contributory factors found to affect semen health and serum-hormone levels negatively among workers using pesticides included lifestyle, level of civilization, knowledge, and proper use of PPE. Our study findings differed, however, and the design of our study was problematic because of inevitable differences between agrochemical-use patterns and practices and the time intervals involved, which play an important role in determining the effects of these variables on hormones when assessing the impact of pesticide exposure on humans. ${ }^{26}$

In Myanmar, OP, organochlorine, and carbamate groups are commonly used. Nevertheless, in this study, most of the groundnut farmers used OP pesticides. These pesticides are used deliberately with no restrictions or precautions, and in addition the empty containers are not disposed of systematically because of the scarcity of land. ${ }^{27}$ The blood-ChE levels among the groundnut farmers were found to be highest during the growing period. The levels found in the current study were higher than those found by Padungtod et al, which revealed that the average $\mathrm{AChE}$ and $\mathrm{PChE}$ levels of the farmers were $2.9 \pm 0.6 \mathrm{U} / \mathrm{mL}$ and $1.5 \pm 0.3 \mathrm{U} / \mathrm{mL}$, respectively. ${ }^{28}$ This study detected some of the symptoms related to the nicotinic action of OPs on the central nervous system and on neuromuscular activity. These symptoms comprise dizziness, headache, weakness, and blurred vision and are highly prevalent, whereas symptoms related to the muscarinic effect of OPs include sweating, hypersalivation, and tremors. These effects have been found to be more marked in the growing period than in the nongrowing period. The most frequently occurring symptoms in the growing period were blurred vision, followed by dizziness, headache, and sweating; all of these 
symptoms were reduced in the non-growing period. These neurotoxic symptoms may be associated with the pesticides' effect on health or may be due to other factors, such as heat exhaustion or lifestyle or socioeconomic factors, which could not be differentiated in this study. Moreover, we could not differentiate the causes of these symptoms in the farmworkers. However, the authors of this study recommend an experimental follow-up study to explore the effect of these symptoms. In contrast, there were no abnormal findings in physical examinations. In this examination, signs and symptoms associated with pesticide toxicity were monitored in such body systems as the respiratory system, central nervous system, and cardiovascular system, and in addition the physical examination chart and performance were checked. The proforma included history of hospitalization and reasons for hospitalization. In terms of the health symptoms reported to occur in the growing and nongrowing periods, a significant difference in dizziness and blurred vision (under the central nervous system) was found $(P<0.05)$ in this study.

The farmworkers were found to use more than one OP pesticide for mixing and spraying on their crops, and used far more than the recommended dosage. Besides that, they were also eating, drinking, and smoking in their workplaces. We thus recommend that safety-risk management should be carried out in this area to avoid the potentially deleterious effects of pesticides through dermal exposure. Advice and training should be offered on correct pesticide-application procedures, as well as the correct quantities to use, in order to minimize risks.

Though the sample size was not small, the generalizability of the findings is restricted to those workers considered to be representative of all Myanmar agricultural workers. Furthermore, this study focused only on the OP pesticides that were used in this community; other groups of pesticides were not investigated. The farmworkers in this study did not want to use PPE, even though they were familiar with it, because of the tropical climate, the inconvenience of wearing it for long working periods, and the expense and limited availability of certain items of equipment. This is because disseminating information about safety measures through online media is not particularly effective, especially regarding the use of protective clothes or aprons, because there is no electricity in the village. A more effective way of educating the workforce is for health workers to explain the pros and cons.

To reverse these trends, education, training, and educational activities on pesticide safety should be established and reinforced. Health education should be provided to avoid the overuse of pesticides and nonadherence to the recommended protocols and to reinforce the use of biopesticides and the adverse effects of pesticides, especially OPs, on health and the environment. The careful and responsible use of pesticides among the farmworkers in order to show consideration for the environment was also found to be lacking.

This study's sample was not small, but the generalizability of the findings is restricted because data collection was limited and so that selected workers may be not considered to be representative of all Myanmar agricultural workers. Future studies should have fewer restrictions and should involve more heterogeneous case groups with an appropriate unexposed control group.

The risks from occupational exposure should be effectively communicated to pesticide users in order to make them better informed, along with guidelines for preventive measures, with an emphasis on proper personal hygiene practices, as well as health-surveillance and education programs. The proficiency levels of the groundnut farmers were found to be unrelated to their level of pesticide risk. Transparent targeting of awareness-based, tactical, complete interventions is necessary to lessen both pesticide exposure and health risks, incorporate training, correct pesticide labeling, implement measures to reduce cost barriers to adopting safe practices, encourage restricted working practices other than PPE, and support integrated pest management. Policies should be updated regularly and regular monitoring programs organized to educate workers about pesticide use and toxicity. Such programs should promote integrated pest management, develop biopesticides, and provide responsible stewardship.

\section{Acknowledgments}

Our sincere thanks are conveyed to the Ethics Committee of the Medical Research Center, Department of Research Center, Lower Myanmar, Ministry of Health, Myanmar, for allowing us to carry out this study on groundnut farmers in Kyauk Kan village, Nyaung-U, Mandalay region, Myanmar. Also, thanks to farmworkers of these villages for their willing participation in this study. This study received funding support from the 90th Anniversary of Chulalongkorn University Fund and the Grant for International Research Integration: Chula Research Scholar (GCURS_59_06_79_01) Ratchadaphiseksomphot Endowment Fund. This research was also supported in part by an National Institute of Environmental Health Sciences, National Institutes of Health-sponsored Center Grant (P30ES005022).

\section{Disclosure}

The authors report no conflicts of interest in this work. 


\section{References}

1. Thein MT. Effects of pesticides on human health: a preliminary study with emphasis on male reproduction, Pyin Oo Lwin, Myanmar. Myanmar Health Sci Res J. 2010;24(3):3-7.

2. Giwercman AH, Rignell-Hydbom A, Toft G, et al. Reproductive hormone levels in men exposed to persistent organohalogen pollutants: a study of inuit and three European cohorts. Environ Health Perspect. 2006;114(9):1348-1353.

3. Swan SH, Kruse RL, Liu F, et al. Semen quality in relation to biomarkers of pesticide exposure. Environ Health Perspect. 2003;111(12): $1478-1484$.

4. Khin MN. Assessment of knowledge and effects of pesticides among the farm workers at Hmawbi Township, Yangon, Myanmar. 2015.

5. Pyae PT. Knowledge, attitude and practice on health effects of pesticide residues among farm workers in Hmawbi Township. Defence Services Medical Academy. 2012.

6. Recio R, Ocampo-Gómez G, Morán-Martínez J, et al. Pesticide exposure alters follicle-stimulating hormone levels in Mexican agricultural workers. Environ Health Perspect. 2005;113(9):1160-1163.

7. Mathur N, Pandey G, Jain GC. Pesticides: a review of the male reproductive toxicity. J Herbal Med Toxicol. 2010;4:1-8.

8. Zenz C. Occupational Medicine: Principles and practical applications. 2nd ed. St. Louis, MO: Mosby-Yearbook Inc. 1988.

9. Dhanushka MA, Peiris LD. Cytotoxic and genotoxic effects of acephate on human sperm. J Toxicol. 2017;2017:6.Article ID 3874817-6.

10. Pant N, Shukla M, Upadhyay AD, Chaturvedi PK, Saxena DK, Gupta YK. Association between environmental exposure to p, p'-DDE and lindane and semen quality. Environ Sci Pollut Res Int. 2014;21(18): 11009-11016.

11. Siriwong W, Thirakhupt K, Sitticharoenchai D, et al. A preliminary human health risk assessment of organochlorine pesticide residues associated with aquatic organisms from the Rangsit agricultural area, central Thailand. Hum Ecol Risk Assess. 2008;14(5):1086-1097.

12. Myanmar Ministry of Health. Health in Myanmar. Available from: http://www.mohs.gov.mm/. Accessed March 11, 2014

13. World Health Organization (WHO). Laboratory Manual for the Examination of Human Semen and Sperm-Cervical Mucus Interaction. Cambridge: Cambridge University Press. 1992.

14. World Health Organization (WHO). Laboratory Manual for the Examination of Human Semen and Sperm-Cervical Mucus Interaction (paperback). Cambridge: Cambridge University Press. 1999.
15. Plant TM, Marshall GR. The functional significance of FSH in spermatogenesis and the control of its secretion in male primates. Endocr Rev. 2001;22(6):764-786.

16. Hofmann JN, Carden A, Fenske RA, Ruark HE, Keifer MC. Evaluation of a clinic-based cholinesterase test kit for the Washington State Cholinesterase Monitoring Program. Am J Ind Med. 2008;51(7): 532-538.

17. Shapiro SS, Wilk MB. An analysis of variance test for normality (complete samples). Biometrika. 1965;52(3-4):591-611.

18. SPSS for Windows. Chicago: SPSS Inc; Rel. 16.0.1.2007.

19. WHO. Laboratory Manual for the Examination of Human Semen and Sperm-Cervical Mucus Interaction. 3rd. Cambridge: Cambridge University Press; 1992.

20. WHO. Laboratory Manual for the Examination of Human Semen and Sperm-Cervical Mucus Interaction. 4th. Cambridge: Cambridge University Press; 1999.

21. World Health Organization (WHO). Physical Status: The use and interpretation of anthropometry. Geneva, Switzerland: WHO. 1995

22. Dohle GR, Smit M, Weber RF. Androgens and male fertility. World $J$ Urol. 2003;21(5):341-345.

23. Wilaiwan W, Siriwong W. Assessment of health effects related to organophosphate pesticides exposure using blood cholinesterase activity as a biomarker in agricultural area at Nakhon Nayok Province, Thailand. $J$ Health Res. 2014;28(1):23-30.

24. Hossain F, Ali O, D’Souza UJ, Naing DK, D'souza U. Effects of pesticide use on semen quality among farmers in rural areas of Sabah, Malaysia. J Occup Health. 2010;52(6):353-360.

25. Pérez-Herrera N, Polanco-Minaya H, Salazar-Arredondo E, et al. PON1Q192R genetic polymorphism modifies organophosphorous pesticide effects on semen quality and DNA integrity in agricultural workers from southern Mexico. Toxicol Appl Pharmacol. 2008;230(2): 261-268.

26. Lipshultz LI, Ross CE, Whorton D, Milby T, Smith R, Joyner RE. Dibromochloropropane and its effect on testicular function in man. J Urol. 1980;124(4):464-468.

27. Myo-Min. Knowledge and Practice of Safety Measures on Pesticide Utilization among Farm Workers in Hmawbi Township. Myanmar: Defence Services Medical Academy; 2008.

28. Padungtod C, Lasley BL, Christiani DC, Ryan LM, Xu X. Reproductive hormone profile among pesticide factory workers. J Occup Environ Med. 1998;40(12):1038-1047.
Risk Management and Healthcare Policy

\section{Publish your work in this journal}

Risk Management and Healthcare Policy is an international, peer-reviewed, open access journal focusing on all aspects of public health, policy, and preventative measures to promote good health and improve morbidity and mortality in the population. The journal welcomes submitted papers covering original research, basic science, clinical and epidemiological

\section{Dovepress}

studies, reviews and evaluations, guidelines, expert opinion and commentary, case reports and extended reports. The manuscript management system is completely online and includes a very quick and fair peerreview system, which is all easy to use. Visit http://www.dovepress.com/ testimonials.php to read real quotes from published authors. 